\title{
EAl Endorsed Transactions

\section{Towards a collaborative experience to generate knowledge: Use of gamification in robotics for Good Agricultural Practices}

\author{
Julieta Lombardelli ${ }^{1,3, *}$, Diego Torres ${ }^{1,2,3}$, Blas Butera ${ }^{1}$ and, Alejandro Fernandez ${ }^{1,3}$ \\ ${ }^{1}$ LIFIA, Facultad de Informatica, Universidad Nacional de La Plata, AR \\ ${ }^{2}$ Departamento de Ciencia y Tecnologia, UNQ, AR \\ ${ }^{3}$ CICPBA, Buenos Aires, Argentina
}

\section{Abstract}

Currently gamification strategies are implemented in the most diverse fields. This paper discusses the design of gamification environment on a collaborative wiki on good agricultural practices. The aim of the project is to present a gamification design is complemented by a robotic interface, aimed at increasing customizing the experience from a cooperative community context. The robot interface also presents the possibility of containing a living organism, linked to the actions of the wiki.

Received on 13 January 2020; accepted on 20 January 2020; published on 22 January 2020

Keywords: Gamification, Agricultural, Robotics, Collaborative

Copyright (C) 2020 Julieta Lombardelli et al., licensed to EAI. This is an open access article distributed under the terms of the Creative Commons Attribution license (http://creativecommons.org/licenses/by/3.0/), which permits unlimited use, distribution and reproduction in any medium so long as the original work is properly cited.

doi:10.4108/eai.13-7-2018.163482

\section{Introduction}

In recent years, gamification has become an effective and versatile strategy to increase participant's motivation in various situations. The term gamification responds to the use of elements that come from the world of gaming and video games, in scenarios that are not playful to primarily motivate users in a given action $[4,10,11]$.

During the last time, the use of gamification has increased, especially in collaborative workspaces [30]. A collaborative knowledge building space (CKBS) is where a specific community or group of individuals relate to the goal of producing content collectively through their contributions [17]. These spaces manage to grow by the sum of the contributions, which implies the active participation of a certain number of individuals. A well-known example of these communities are Wikis, and a famous example is Wikipedia.

Gamification can be used to motivate participation in these types of communities. Here, collective growth is the primary goal. By contrast, individual growth

*Corresponding author.Email:julieta.lombardelli@lifia.info.unlp.edu.ar could be developed by archetypical strategies such as score tables and points. Indeed, the use of gamification strategies aimed at personal growth in CKBS could generate the opposite effect and discourage collective participation [31].

Therefore, gamification in collaborative communities requires an analysis that is specifically tailored to their environment, and that shapes the particular characteristics of each community [30]. In this sense, Gamification must be appropriate to the group of people and the field of knowledge generation. Also Gamification must be relevant to the group of people and the area of knowledge generation. This lead to the objective of motivate the practices of collaborative construction, to motivate the construction of specific knowledge, and increase long-term commitment based on the terms and beliefs of users [7].

This work explores the design of a specific gamification strategy in a wiki of Good Agricultural Practices (GAP) from its double experimental axis: virtual environment and bio-art robotic development. From the gamification strategy applied to the wiki, it is analyzed to expand the scope of game strategies as a motivational engine through a virtual gamification installation 
through the web browser, complemented with a tangible robotic facility. In this way, this article observes the main characteristics acquired by a knowledge building community (KBC) motivated through gamification.

This article is organized in the following. Section 2 describes the collaborative experience concept in a KBC. Then, Section 3 introduces the specific gamification process in a KBC from MDA framework perspective. Next, in Section 4, intensive best agricultural practices are defined. Hypothesis, methodology, and the approach for gamification in a KBC are introduced in Section 5. Section 6 details a discussion and learned lessons. Related works of gamification in KBC are detailed in Section 7. Finally, Section 8 details conclusions and further work.

\section{Collaborative experience in a KBC}

Information technologies and specifically the Internet, "has provided the infrastructure for everyone to enjoy participating in collaborations based on their interest" [19]. Progressively, collaboration networks and spaces begin to emerge where it is possible to promote the construction of knowledge in a collaborative way.

Knowledge building communities (KBC) are communities of practice where the main objective is to produce content through individual contributions. The complexity of the task of generating new knowledge is reduced because the results are the combination of multiple contributors instead of only one person [36]. Good examples of $\mathrm{KBC}$ are projects based on the production of content in the form wiki $[23,38]$. The most famous is Wikipedia.

\section{Gamification with MDA}

The gamification design examines the application of elements taken from games and videogames to non-recreational environments, without modifying its central structure $[9,11,21]$. Gamification is used as a tool to increase motivation and is implemented in numerous different fields [16].

Gamification acquires different characteristics depending on the context in which is applied [5]. Therefore, when choosing gamification elements, it is necessary to know the needs of the users: a single person context, in a small group of people, or a large, open, and collaborative community [37].

In this sense, there are several structures that a gamification design can acquire, ranking different strategies according to the context. Following the study of Cugelman [7], seven main strategies can be enumerated:

- Goal setting: Committing to achieving a goal

- Capacity to overcome challenges: Growth, learning, and development
- Providing feedback on performance: Receiving constant feedback through the experience

- Reinforcement: Gaining rewards, avoiding punishments

- Compare progress: Monitoring progress with self and others

- Social connectivity: Interacting with other people

- Fun and playfulness: Paying out an alternative reality

However, to design successful gamification, it is necessary to contemplate a framework that fits the sought objectives. Several studies indicate that there are frameworks proposals which are especially adapted to address gamification strategies [2][5]. Nevertheless, many of these frameworks derive from a more generic framework called MDA from the acronym Mechanics, Dynamics, and Aesthetics. The MDA [18], is a framework that is analyzed from the academic field and is widely used in the design of games and video games.

It proposes to partition into three axes the composition of a gamified system. These axes are:

- Mechanics, which describes the particular components of the game, such as rules, actions, and control mechanisms.

- Dynamics that describes the system, namely the development over time of these mechanics through the responses of users and other factors that may intervene in the system. They describe behaviors and interactions. For example in teamwork environments or groups of individuals with common goals can lead to dynamics such as cooperation [1].

- Aesthetics, which are the emotional responses in users when they interact with the system. Aesthetics arises by following mechanics and generating dynamics.

Hunicke et al. [18] distinguishes eight categories of aesthettics, but without limiting them to expand. These categories are :

- Sensation, the game as sense-pleasure linked to visual effects.

- expression, the game as self-discovery, related to creativity

- Fantasy, the game as make-believe focused on imagination and world creation.

- Narrative, the game as a drama where the story guides the actions of the players. 
- Fellowship, the game as a social framework, where the player is part of a community.

- Challenge, the game as an obstacle that leads the player to overcome and play again.

- Submission, the game as a pastime.

- Discovery, the game as uncharted territory.

The MDA framework contemplates that these three axes can be understood by both from who designs the game experience, as well as from the one who experiences it, the player.

\section{1. $M D A$ in a $K B C$}

In order to design a gamification experience in a collaborative environment, this work begins the design from the aesthetic axis in the MDA framework. From this axis, the user experience is analyzed as part of the specific Intensive Agricultural Best Practice (IABP) community rather than an individual player.

Understanding, therefore, that aesthetics and gaming experience starts from the relationships of a community of practice, as a first step, we analyze which aspects are motivating to increase participation in collaborative spaces.

Recent research [6, 33], conclude that some typical gamification elements may not be suitable for implementation in collaborative work communities. For example, if the objective is the motivation to work in a community in a collaborative knowledge environment, competitiveness can result in the opposite effect as it is an element that focuses on biasing the members of the community. Competitiveness as a strategy is diagrammed from gamification through items such as the score tables or leaders identification. In short, these elements may result in the opposite effect to motivate collaboration and collective contribution.

From MDA aesthetics concepts, the desired category of aesthetics for a KBC should be directed to Fellowship, to deepen cooperation among individuals in the community; Challenge to increase motivation and commitment; and Narrative, to react with a story in common the actions of the community and thus motivate an appropriation of the project.

On the other hand, cooperativism is a value that emerges in a collaborative community like a Wiki, which consequently leads to consider cooperative gamification. This type of gamification has the characteristic that several players share a common goal, but it is through promoting individual actions that they are motivated to meet that goal and encourage the actions of others. These actions lead to results that influence the overall objective, such as positive interdependence, or shared challenges for a team of players [31, 33].
Avatars are other gamification resources associated with the Narrative. Avatars are visual representations of participants in the digital environment. generally avatars are associated with individual engagement because individuals can register an image or symbol to represent them when performing activities within the virtual space, and avatars serve to personalize the individual experience of a gamified activity, which increases the emotional attachment to the activity [5]. However in this design, the avatar category articulates with a narrative set in relation to the experience of a community, creating a cooperative customization.

\section{4. iGAP: Best Agricultural Practices}

iGAP is a wiki site focuses on those practices related to intensive horticultural activity in aspects that may be subject to improvement. This is framed in what is currently considered as Good Agricultural Practices (BPA). They are practices that are more environmentally friendly and less harmful to natural resources, workers' health, and the safety of food products promoted by the Food and Agriculture Organization of the United Nations (FAO).

GAPs are the available knowledge applying in the sustainable use of basic natural resources for the production, in a benevolent way, of safe and healthy food and non-food agricultural products, in economic viability and social stability. It is about knowledge, understanding, planning and measurement, record, and management aimed at achieving specific social, environmental, and productive objectives ${ }^{1}$. GAPs goals are: Ensure food safety, Produce in a way that protects the environment and avoids its degradation, Ensure job well-being, and Obtain quality products according to consumer demand.

The wiki includes a description, goals, and methodologies of each good practice defined in GAP. Also, the wiki contains tutorials, external sites about the agricultural field, and legal documentation.

\section{The gamification of iGAP}

In a community of knowledge practice linked to the discipline of agriculture, a gamification process to seek motivation and active community participation is designed with the symbolic elements that derive from the analysis of the community's own relationships.

The symbolic connotation applied to an environment linked to a game determines, to a large extent, what the player assumes and interprets when experiencing the scheduled spaces. Both gamification and video games can be considered as sign systems, as well as any other

\footnotetext{
1 http://www.fao.org/newsroom/en/news/2007/1000475/index. html 
culture artifact, where the symbol is interpreted as part of that system.[13]. The symbol is understood as an image that represents something in a certain way and is interpreted from a given cultural environment. [15]

In the case of iGAP, the main goal of the gamification strategy is to motivate the growth of the GAP pages through community participation. For this, the implementation of an avatar symbol is the representation of growth and personalizing of each GAP wiki page.

The selected symbol is a tomato plant. This plant represents typical local vegetables (TLV). This ad hoc definition was conceived to distinguish genetic materials that are characterized by being botanical varieties and having a prolonged time in the same area. TLV are being recognized by producers and consumers of the local community [14]. Tomato plant is the most representative of the horticultural area in La Plata, Argentina, which is called "horticultural green belt," where iGAP arises.

From this analogy, a double axis of gamification is designed for the active participation of the wiki: on the one hand, an axis related to the praxis of the wiki is conceived from the online digital platform, which we will call "virtual gamification". On the other, the axis is related to a tangible aspect, materialized in a robotic installation, connected to the progression of the "virtual" space that we will call "robotic gamification."

Also, the two main aesthetic elements selected of MDA are developed. First, the items that contribute to fellowship to promote the collaborative work represented in the general health concept of the wiki through the robotic installation. Second, the use of MDA challenge aesthetic to encourage the improvement in the objectives visualized through the progression of each page.

\subsection{Virtual space: the wiki}

In order to facilitate the access to a number of users that are not accustom to this technologies, an intuitive reading environment was designed. Indeed, the progression gamification element was proposed.

A tomato plant, as symbol that represents the growth of each page, visualizes the progreession process among three states:

1. Establishment. This represents a new page, without ratings. The content of this page is waiting for the approval of the community members in both as good practice and content quality.

2. First flowering. This state shows that the page includes a number of valid activities and good ratings of the community. The content grows, new links, images or other content was added. In this way, the content goes deeper into detailing the proposed good practice or activities related to them.

3. Fruit ripening. Here the page is fully validated by the community as a good practice in agriculture. Although the page may continue to have modifications, from this state the activity in it tends to decrease, resulting in verified content for consultation and subsequent practical application.

The quality (health) aspect is developed through a wiki API based on the RatePage 0.2.0 extension. This extension displays on the side of the wiki page a validation system symbolized through stars, which any user can determine on a scale of 1 to 5 stars if the content presented is correct and is framed in one of the iGAP sections.

Likewise, each user within their profile has a progress bar. Progression bars extend the concept of granular progression even more than badges and levels. Progression bars are a continuous visual representation of progress towards the next goal or achievement. By showing ongoing progress, also if the individual increments are small, the progression bars aim to demonstrate to the participant that they are continuously progressing, which provides motivation. Showing to a participant is close to reaching a goal also offers an additional increase in motivation. A person who is asked to "exceed the line" and then reach the next target.

\subsection{Robotic gamification}

A robotic installation is designed to respond to the states of iGAP. This establishes an analogy that exceeds the limits of the wiki screen. The main objective is to generate greater empathy with the community of practice by establishing a physical figure that acts rhetorically and dependent on the actions that users perform in the virtual environment.

As a principle in the design, we work on the basis of the concept of robotic art. A broad definition of this artistic discipline was developed by Eduardo Kac [20], stating that a robotic work of art is a type of art that uses robotics or automated technology, from its broadest perception prioritizing behavior over form and that It can be complemented with computer technology and sensors.

It should be noted that the concept of robotic art emphasizes that the robot is the work and that the work is not only what can be created or produced by the robot. In robotic art, the artist does not disappear and is not replaced by the robot, even if it acts automatically, unlike the imaginary where the robot replaces human actions [22]. 
From this sense, robotic work is associated with the design of movement or actions to be executed by the robot, which generates an illusion of autonomy and artificial intelligence. This type of work has the potential to establish a strong projection with the viewer since the one who observes and interacts can project their own interpretation of the robot's attitudes, finally attributing resolution and autonomy capabilities that they may not have. [27]

Following the objective of generating a projection that can motivate an empathy that can last over time, in the design of the BPAi wiki robotics installation, the strategies of generating a physical movement and an immediate visual response to the stimuli are considered from the wiki

Shape: conceptualization and implementation. The design of the iGAP robot is solved externally following the symbolic parameters of the virtual avatar of the wiki pages, the tomato plant. A container, with a spherical form like a tomato, is designed and materialized by 3D printing technology. This robot is located in a controlled environment, on land on the ground.

The aesthetic search, in this case, was guided to prioritize a harmonic articulation between three vector axes: the movement factor, the visualization of the state communication parameters, and the ability to selfsustain a self-sustaining system to maintain a plant species.

The movement axis was implemented with a system of actuator motors with the strength and ability to move over land and support the weight of its own body. For the axis of visualization of states, light-emitting diodes (LEDs) of Pixel Led type are implemented, to be programmed with different sequences of color and movement, according to the actions that are performed in the wiki. Finally, for the axis of transport of the plant, a spherical figure is designed using 3D technology that refers to the abstraction of the tomato, capable of containing soil over the electronics and the hardware that monitors the health of the real plant. Likewise, the plant will be living with LED lights, which also influences its growth.

LED lights have shown through various studies [28] that they can be beneficial in different aspects of plant growth in controlled situations. Such benefits can be listed from favoring morphological, anatomical, and physiological attributes, such as the lengthening of shoots, to regulating the photosynthetic capacities of plants grown in vitro, by the spectral qualities of LEDs. Another advantage of the use of LEDs is the ability to emit monochromatic colors from the same diode, generating light at specific wavelengths, such as red or blue lights, minimizing the impact on the plant which only receives what it needs and is not overstimulated as with the wavelengths of fluorescent light. [12]
Therefore, the design of the robot's housing proposes surrounding the plant with spaces for the lights (to ensure that the plant coexists with the lights) arranged in small modules between the surface of the plant.

Actions and movements. With the aim of generating an immediacy in the visualization of the states, pixeltype LED lights are implemented. Pixel LEDS can be programmed from a free hardware platform Arduino based on a board with a microcontroller and a development environment. Arduino hardware allows the robot to approach a system based on the Internet of Things (IoT), which enables the flow of data from the Internet as well as the monitoring by sensors of physical environments.

In this way, the robot is linked to the health of the iGAP wiki. The robot receives the data of the gamification API implemented in it. Consequently, if the wiki has users activity and it grows its knowledge, the robot moves generating grooves in the earth. Parallel to the movement, it produces a play of lights that refers to virtual states, associated with three specific actions on the wiki:

- Establishment: In this action the robot is static and shows the general state of the wiki and expects new actions in the wiki. The lights have a Fade-in and Fade-out effect, which refers to an intermittent beat. The colors vary according to the general state of the wiki. The API generates an average of the activity that is updated every 10 seconds, showing a color palette that will vary from a blue with moderate brightness to gradually become an intense blue. As the wiki continues to grow, the color of the LEDs will change until it reaches a deep red. This chromatic choice responds to studies conducted on plants and vegetables [24, 28], which indicates that plants respond differently to the stimuli of the color of the lights. Thus, red wavelengths (600 to 700 $\mathrm{nm})$ are efficiently absorbed by plant pigments, while blue light has an important effect on other aspects of plant growth such as water relations and $\mathrm{CO} 2$ exchange, elongation of the stem, and phototropism.

- First flowering: In this action, each time a user enters the wiki through login, the robot makes a 2 (two) second advance and a 90 degrees rotation. At the same time, a figure formed by a sequence of four LEDs is generated in the lights, which runs through the entire surface of the robot, acquiring the color of the current state of health of the wiki, varying between blue and red as appropriate.

- fruit ripening: every time a change is made in any of the pages, a new BPA is generated, or a text is edited. The robot will make an advance of 
3 (three) seconds and a more closed turn. The lights will show a new pattern, which includes the sequential color change of all the LEDs surrounding the robot. This generates a wave effect with colors that vary between blue, violet, and red.

These states are articulated as events happen in the virtual space. The state (a) establishment, is the constant state that progressively varies the chromaticity depending on the health of the wiki.

This representation (in the movement and in the states of the lights of the robot) contributes to consider a staging where a relation of dependence of the physicaltangible factor is generated with the space of generation of virtual license.

If the wiki has good health, the robot moves, shines, and generates active states. Otherwise, it remains stopped in the same place, as long as the activity of the wiki is not updated, lowering the brightness of the lights, with the possibility of being completely off.

Likewise, the movement of the robot generates furrows on the earth where it moves, which, potentially, can be observed as a graphic pattern on the ground, a consequence of the collaborative work of the community in the wiki.

\subsection{Self-sustainable bioart}

The robot's structured is completed with a section to transport a plant and to consequentely generate a more direct relationship with the representation of the life and health of the wiki.

In the upper part, between the LED lights, the growth of some species of non-perennial vegetables and plants is arranged. Humidity and temperature are controlled by sensors connected to the arduino board, which are updated according to the IoT devices. The different IoT devices measure the humidity of the soil of the plant and in case of requiring a higher level of water they trigger drip irrigation until a healthy humidity level is obtained.

The plant, in contact with the light states of the robot, will vary its growth depending on the health of the wiki. In parallel with the drip flow of the irrigation system, it is related to the information obtained from the wiki.

This relationship generates a delicate balance between what the robot physically perceives, through the health of the plant, considering the values that the sensors capture on soil moisture, for example, and the data of the community's activity when working collaboratively in generating and disseminating more knowledge about good agricultural practices.

When a living being is linked to the robotic entity, a direct analogy is established with the community and the concept of sustaining life. It is in this sense that the self-sustaining factor is established, where an

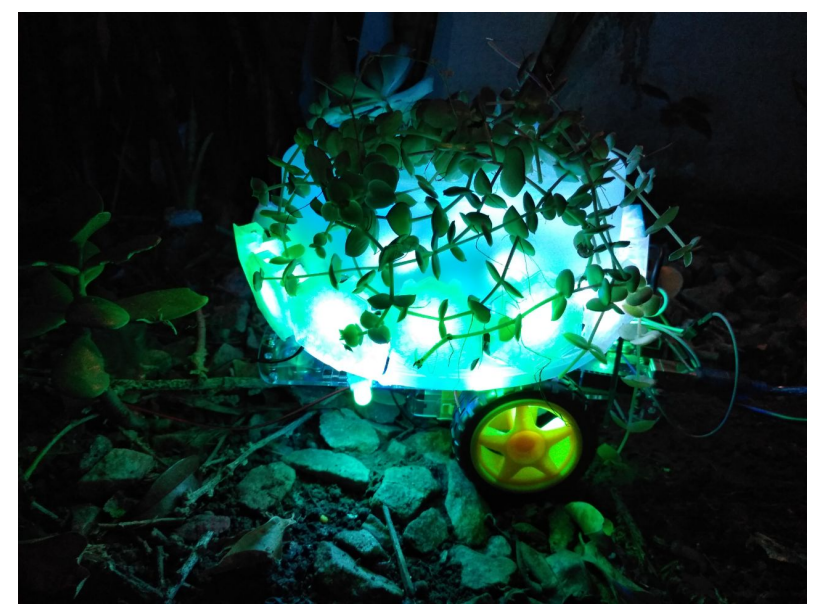

Figure 1. Prototype 1

entire community performs joint actions to maintain an irrigation flow that is healthy for the plant, as well as generate the robot to continue with a light system that can favor the plant growth

\subsection{Prototype}

For the design of the robot housing, we began by studying how to integrate the LED lights with the structure that the plant would contain. In the figure ref 1 the first prototype that is oriented to formalize the amount of LEDs to be used and a formal base structure to contain the electronic elements and actuators are displayed.

Based on the results obtained, prototype 2 is carried out to analyze the possible containers of the LED modules. For this, tests are carried out with $3 \mathrm{D}$ technology printing, based on models to verify the modularity of the LEDs, and that can surround the structure of the plant.

In the tests that followed, it was tested how to integrate the plant into the modules of the LED lights. In the figure 2 the prototype 2 can be observed, including the modules integrated to the plant and engines.

Finally, the design of a semi-spherical scheme is resolved, from which it is possible to arrange the LEDs integrated to the plant, above the electronic section. Figure 3 shows the design scheme, representing the upper part of the housing of the robot, raised in function of containing earth and generating spaces for a plant to grow, related to the green belt.

The rest of the robot housing is designed to contain the electronics and hardware that controls the robot.

To control the robot, an extension for semantic mediawiki was developed that performs the gamification and has statistical controls. This extension is built through an api that allows access to specific data of the 


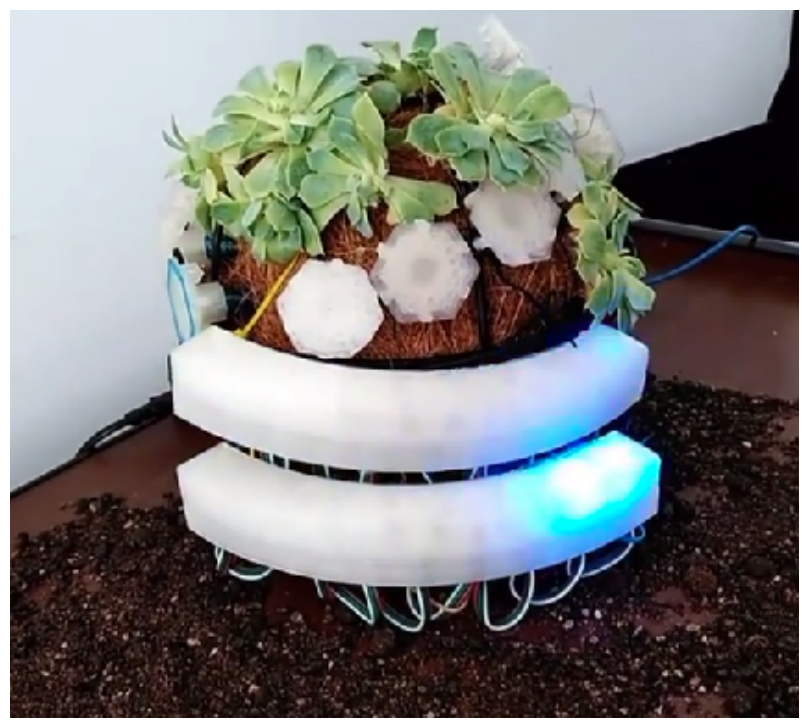

Figure 2. Prototype 2

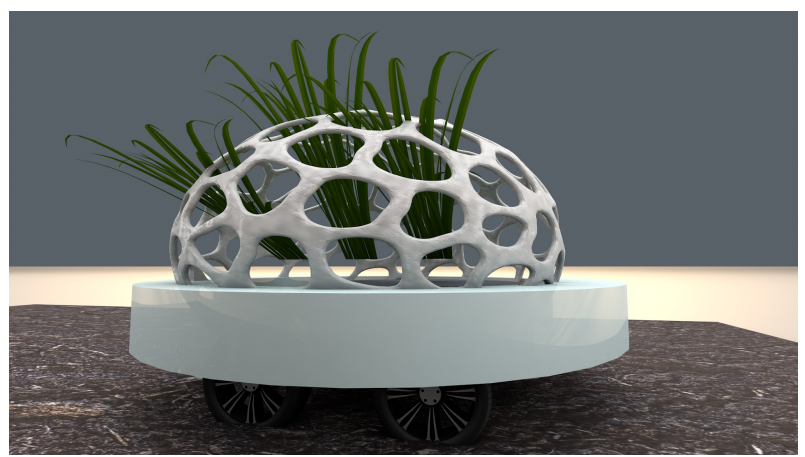

Figure 3. Prototype 3

wiki, for example to obtain the percentage of the voted pages. Through this API, an extension is developed so that an external hardware to the web, in this case the Arduino environment, can query data from the wiki. For this, an ethernet web client is built where the server is the BPAi wiki. Since the use of the API, arduino periodically consults a particular URL of the API that returns the latest information on the wiki: percentage of votes, general status of the wiki, if there was a login or if someone edited a page.

The main tasks that the API extension executes are:

- being able to rate pages

- Check if a user created / edited a page (using API).

- Check if a user logged into the wiki (via API).

- Check global status of the wiki.

The figure 4 shows a screenshot of the API extension running on top of a mediawiki environment, parallel to the BPAi wiki.

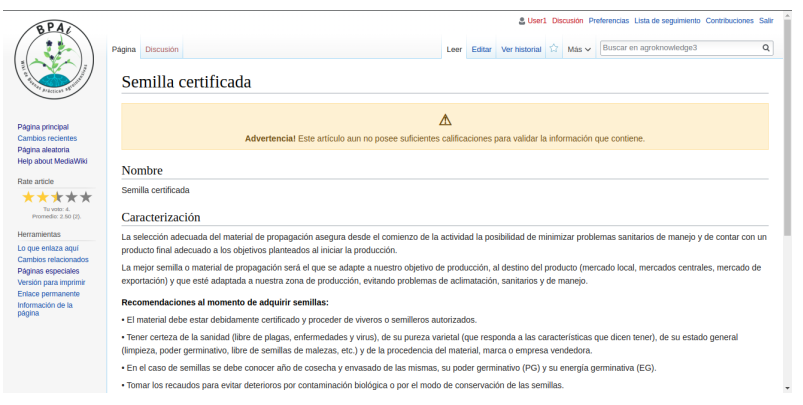

Figure 4. An extension API for the BPAi wiki. Screen capture

The robotic device was developed on an Arduino architecture, using ethernet boards connected to the wiki API extension. In the components linked to arduino that is implemented in the robot, in addition to the motors, a soil moisture sensor is used to monitor the general condition of the plant.

\section{Discussion}

This research brings together a group of different disciplines, which are articulated in a double scenario, configured based on a main objective: to generate specific knowledge collectively.

Among these disciplines, the concept of Bioart arises, which in a broad definition responds to works that contain some kind of biological component [8], combining art, science and technology and modifying the viewer's place in the work [26].

Bioart combines different disciplines such as biology, genetics, biotechnology etc. With these techniques you can modify or model biological aspects, which constitute the work [3].

Therefore, this work presents features that can be framed in what is called bioart, by establishing a kind of dialogue and analogy between the health of the plant arranged in the robot and the health of the wiki.

This design seeks to generate a direct empathic projection with the community, and make it participate with its collaborative actions of the possibility of holding together, a living organism. It is also part of the design to consider that the plant is directly related to the object of knowledge and work of the community, so that the transfer that is intended is direct.

This real figure is easier to understand than the virtual concept of health. This analogy seeks to minimize the technological gap with producers. On the other hand, by visualizing the poor health of the plant, it is possible to indirectly establish a relationship to the poor health that food could have if producers do not use these good practices.

The main discussion that opens in scenarios where living organisms are used for aesthetic metaphors, are linked to the relationship of ethics that involves the aesthetic decisions [35]. From this sense, it is 
proposed to solve an integral design in the BPAi robotic installation, which has the minimum impact on the health of the plant and where the visual metaphor is more specific and clear from the light routines and robot movements.

This design of the installation format that generates a minimum impact is still under development and is linked to an efficient and self-sustaining irrigation system that can respond to the plant health monitors made by the sensors in the robot.

\section{Related work}

Robotics and living organisms has references in artists such as Ken Rinaldo and his research in symbiotic interfaces, to communicate states and actions of living beings through robots [34]. These works are not directly related to the gamification concept, although in some specific cases such as Augmented Fish Reality, 2004, a search can be observed to motivate certain behaviors in living beings with which the installation interacts.

From another perspective, the research work on tangible gamification carried out in the Royal Museums of Art and History, Brussels, Belgium [32], represents a background on the potential of conceiving physical interfaces, as a strategy that complements the design of gamification, such as an engine to generate motivation about groups in a collaborative way.

The work of [25] discusses the gamified design of the Close the door app, with focus on collaborative communities practice.

The research work in the field of tangible gamification is very recent as establishing a generalized analysis, unlike the specific crowdsourcing gamification, which presents differentiated features as analyzed by [29]

\section{Conclusions}

Through this article, a gamification design is presented, which is proposed for a web environment, applied to a wiki linked to agriculture. This gamification proposal seeks in its design to also develop an environment that exceeds the web environment, and promote a robotic installation directly linked to the implemented gamification elements.

This first design phase is executed on a scenario that acts as a mirror of the wiki, to prototype and test the extensions that are linked to the development software of the wiki.

The first prototypes of the extension displayed favorable results regarding the correct integration of the API into the mediawiki environment. The routines of the LEDs in the Arduino environment respond to the extension in real time.

For the next phase of work, the objective is to integrate a test stage involving users of the community, in addition to deepening the execution of the robotic installation.

\section{References}

[1] Atighi Lorestani, E., Khalili, M. et al. (2017) How lighting dynamics create social interactive game. In $D S$ 88: Proceedings of the 19th International Conference on Engineering and Product Design Education (EEPDE17), Building Community: Design Education for a Sustainable Future, Oslo, Norway, 7 \& 8 September 2017: 680-685.

[2] AZOUZ, O. and LEFDAOUI, Y. (2018) Gamification design frameworks: a systematic mapping study. In 2018 6th International Conference on Multimedia Computing and Systems (ICMCS): 1-9. doi:10.1109/ICMCS.2018.8525900.

[3] Benítez, L. (2009) Bioarte. la vida como material. Disturbis (5): 0001-8.

[4] Beza, E., Steinke, J., van Etten, J., Reidsma, P., Fadda, C., Mittra, S., Mathur, P. et al. (2017) What are the prospects for citizen science in agriculture? \{Evidence\} from three continents on motivation and mobile telephone use of resource-poor farmers. PloS One 12(5): e0175700. doi:10.1371/journal.pone.0175700.

[5] Buckley, P., Noonan, S., Geary, C., Mackessy, T. and Nagle, E. (2019) An Empirical Study of Gamification Frameworks. Journal of Organizational and End User Computing 31(1): 22-38. doi:10.4018/JOEUC.2019010102, URL http://services.igi-global.com/resolvedoi/ resolve.aspx?doi=10.4018/ JOEUC. 2019010102.

[6] Cordero-Brito, S. and Mena, J. (2018) Gamification in the social environment: a tool for motivation and engagement. In Proceedings of the Sixth International Conference on Technological Ecosystems for Enhancing Multiculturality (ACM): 640-643.

[7] Cugelman, B. (2013) Gamification: What it is and why it matters to digital health behavior change developers. JMIR Serious Games 1(1): e3. doi:10.2196/games.3139.

[8] DEL Rincón, D.L. (2015) Bioarte: arte y vida en la era de la biotecnología, 33 (Ediciones Akal).

[9] Deterding, S., Dixon, D., Khaled, R. and Nacke, L. (2011) From game design elements to gamefulness: defining gamification. In Proceedings of the 15th international academic MindTrek conference: Envisioning future media environments (ACM): 9-15.

[10] Deterding, S., Khaled, R., Nacke, L. and Dixon, D. (2011) Gamification: toward a definition. Chi 2011 : 12-15doi:978-1-4503-0268-5/11/0, URL http:// gamification-research.org/wp-content/uploads/ 2011/04/02-Deterding-Khaled-Nacke-Dixon.pdf. 9781450302685.

[11] Domínguez, A., Saenz-De-Navarrete, J., De-Marcos, L., Fernández-Sanz, L., Pagés, C. and Martínez-Herráiz, J.J. (2013) Gamifying learning experiences: Practical implications and outcomes. Computers and Education 63: 380-392. doi:10.1016/j.compedu.2012.12.020.

[12] Dutta Gupta, S. and Jatothu, B. (2013) Fundamentals and applications of light-emitting diodes (leds) in in vitro plant growth and morphogenesis. Plant Biotechnology Reports 7(3): 
211-220. doi:10.1007/s11816-013-0277-0, URL https://doi.org/10.1007/s11816-013-0277-0.

[13] Folkerts, J. (2010) Playing Games as an Art Experience: How Videogames Produce Meaning through Narrative and Play (Leiden, The Netherlands: Brill | Rodopi), 97 - 117. URL https://brill.com/view/book/edcoll/ 9789042030831/B9789042030831-s007.xml.

[14] Garat, J., Otero, J., Ahumada, A., Bello, G. and Terminiello, L. (2008) El enfoque sial como instrumento de intervención: el caso el tomate platense y las hortalizas típicas locales en el cinturón verde de la plata, argentina. In Actas del IV congreso internacional de la RED SIAL.

[15] Goodman, N. (2010) Los lenguajes del arte: Aproximación a la teoría de los símbolos, Paidós Estética (Ediciones Paidós). URL https://books.google.com.ar/books? id $=91 \mathrm{gU} \_\mathrm{gAACAAJ}$.

[16] Hamari, J., Koivisto, J. and Sarsa, H. (2014) Does \{Gamification $\}$ WWork\}? - AA $\{$ Literature $\}$ Review of \{Empirical\} \{Studies\} on \{Gamification\}. In 2014 47th \{Hawaii\} \{International\} \{Conference\} on \{System\} \{Sciences\}: 3025-3034. doi:10.1109/HICSS.2014.377.

[17] Hoadley, C.M. and Kilner, P.G. (2005) Using technology to transform communities of practice into knowledgebuilding communities. SIGGROUP Bull. 25(1): 31-40. doi:10.1145/1067699.1067705, URL http://doi.acm. org/10.1145/1067699.1067705.

[18] Hunicke, R., LeBlanc, M. and Zubek, R. (2004) MDA: A Formal Approach to Game Design and Game Research. Workshop on Challenges in Game AI : 14doi:10.1.1.79.4561.

[19] IвA, T. (2010) An autopoietic systems theory for creativity. Procedia-social and behavioral Sciences 2(4): 6610-6625.

[20] KAC, E. (1997) Foundation and development of robotic art. Art Journal 56(3): 60-67. doi:10.1080/00043249.1997.10791834, URL https: / / www. tandfonline.com/doi/abs/10.1080/ 00043249.1997. 10791834. https: / / www. tandfonline. com/doi /pdf/10.1080/00043249.1997.10791834.

[21] KAPP, K.M. () The gamification of learning and instruction : game-based methods and strategies for training and education (Wiley San Francisco). URL https://books.google.es/books/about/ The $\left\{_{-}\right\}$Gamification $\left\{_{-}\right\}$of $\left\{_{-}\right\}$Learning $\left\{_{-}\right\}$and $\left\{_{-}\right\}$Instruc html?id=M2Rb9ZtF xccC $\{\&\}$ redir $\left\{\_\right\}$esc $=y$.

[22] Kroos, C. (2016) The Art in the Machine (Singapore: Springer Singapore), 19-25. doi:10.1007/978-98110-0321-9_2, URL https://doi.org/10.1007/ 978-981-10-0321-92.

[23] Leuf, B. and Cunningham, W. (2001) The Wiki Way: Quick Collaboration on the Web (Addison-Wesley Professional).

[24] Massa, G.D., Kim, H.H., Wheeler, R.M. and Mitchell, C.A. (2008) Plant productivity in response to led lighting. HortScience horts 43(7): 1951 - 1956. URL https://journals.ashs.org/hortsci/view/ journals/hortsci/43/7/article-p1951.xml.

[25] Massung, E., Coyle, D., Cater, K.F., Jay, M. and Preist, C. (2013) Using crowdsourcing to support proenvironmental community activism. In Proceedings of the SIGCHI Conference on Human Factors in Computing Systems, CHI '13 (New York, NY, USA: ACM): 371-380. doi:10.1145/2470654.2470708, URL http://doi.acm. org/10.1145/2470654.2470708.

[26] Matewecki, N. (2014) Las figuras de espectador en el arte contemporáneo. el caso del bioarte. Boletín de Arte (14): 40-48. URL http: //papelcosido. fba.unlp.edu . ar/ojs/index.php/boa/article/view/52.

[27] Mondada, F. and Legon, S. (2001) Interactions between art and mobile robotic system engineering. In International Symposium on Evolutionary Robotics (Springer): 121-137.

[28] Morrow, R.C. (2008) Led lighting in horticulture. HortScience horts 43(7): 1947 - 1950. URL https: // journals.ashs.org/hortsci/view/ journals / hortsci/43/7/article-p1947.xml.

[29] Morschheuser, B., Hamari, J. and Koivisto, J. (2016) Gamification in crowdsourcing: A review. In 2016 49th Hawaii International Conference on System Sciences (HICSS): 4375-4384. doi:10.1109/HICSS.2016.543.

[30] Morschheuser, B., Hamari, J., Koivisto, J. and Maedche, A. (2017) Gamified crowdsourcing: Conceptualization, literature review, and future agenda. International Journal of Human-Computer Studies 106: 26 - 43. doi:https://doi.org/10.1016/j.ijhcs.2017.04.005, URL http://www.sciencedirect.com/science/ article/pii/S1071581917300642.

[31] Morschheuser, B. and Maedche, A. (2019) Cooperation or competition - When do people contribute more? A field experiment on gamification of crowdsourcing. International Journal of Human-Computer Studies 127: 7-24. doi:10.1016/J.IJHCS.2018.10.001, URL https://www.sciencedirect.com/science/article/ pii/S1071581918305822.

[32] Nofal, E., Ramakers, R., Hameeuw, H., Boschloos, V. and Vande Moere, A. (2017) Collaborative tangible gamification of built heritage for young museum visitors.

[33] Prestopnik, N.R. and Tang, J. (2015) Points, stories, worlds, and diegesis: Comparing player experiences in two citizen science games. Computers in Human Behavior 52: 492-506. doi:10.1016/j.chb.2015.05.051, URL http://www.sciencedirect.com/science/article/ pi i/S074756321500432X.

[34] Rinaldo, K. (2016) Trans-Species Interfaces: A Manifesto for Symbiogenisis (Singapore: Springer Singapore), 113147. doi:10.1007/978-981-10-0321-9_7, URL https:// doi .org/10.1007/978-981-10-0321-9_7.

[35] Stracey, F. (2009) Bio-art: the ethics behind the aesthetics. Nature Reviews Molecular Cell Biology 10(7): 496-500.

[36] Torres, D., Díaz, A., Cepeda, V., Correa, F. and Fernández, A. (2017) Nodos: Encyclopedia of the performing arts. Revista Colombiana de Computación 18(2): 33-46.

[37] XI, N. and Hamari, J. (2019) Does gamification satisfy needs? A study on the relationship between gamification features and intrinsic need satisfaction. International Journal of Information Management 46: 210-221. doi:10.1016/J.IJINFOMGT.2018.12.002, URL https://www.sciencedirect.com/science/article/ pii/S0268401218307436. 
Julieta Lombardelli et al.

[38] ZhaO, X. and Bishop, M.J. (2011) Understanding and supporting online communities of practice: lessons learned from \{Wikipedia\}. Educational
Technology Research and Development 59(5): 711-735. doi:10.1007/s11423-011-9204-7, URL https://doi.org/10.1007/s11423-011-9204-7. 